Article

\title{
Use of Unmanned Aerial Vehicles (UAVs) and Photogrammetry to Obtain the International Roughness Index (IRI) on Roads
}

\author{
Matías Prosser-Contreras ${ }^{1}$, Edison Atencio ${ }^{1, *}$, Felipe Muñoz La Rivera ${ }^{1,2,3}$ (D) \\ and Rodrigo F. Herrera ${ }^{1}$ (D) \\ 1 School of Civil Engineering, Pontificia Universidad Católica de Valparaíso, Av. Brasil 2147, \\ Valparaíso 234000, Chile; matias.prosser.c@mail.pucv.cl (M.P.-C.); felipe.munoz@pucv.cl (F.M.L.R.); \\ rodrigo.herrera@pucv.cl (R.F.H.) \\ 2 School of Civil Engineering, Universitat Politecnica de Catalunya, 08034 Barcelona, Spain \\ 3 International Center for Numerical Methods in Engineering (CIMNE), 08034 Barcelona, Spain \\ * Correspondence: edison.atencio@pucv.cl
}

Received: 11 November 2020; Accepted: 7 December 2020; Published: 8 December 2020

\begin{abstract}
Road inspection and maintenance require a large amount of data collection, where the main limiting factor is the time required to cover long stretches of road, having a negative impact on the optimization of the work. This article aims to identify modern tools for road maintenance and analysis. To carry out the research, recent methodologies are used to guide the work in different stages to adequately justify the processes involved. Using unmanned aerial vehicles (UAVs), cameras, and GPS, three-dimensional virtual models are reconstructed, which are useful for extracting the necessary information since they allow for accurate replication of the captured. In this way, it is possible to obtain longitudinal profiles associated with the road, and with it, the international roughness index (IRI) is calculated, which gives results within $0.1(\mathrm{~m} / \mathrm{km})$ of the certified official results, which shows its potential use and development.
\end{abstract}

Keywords: road engineering; unmanned aerial vehicles (UAVs); photogrammetry; longitudinal profile; international roughness index; IRI

\section{Introduction}

Roads must be safe and kept in good condition. Maintenance management is an essential operation that must be carried out effectively to maintain, repair, and rehabilitate roads. Many aspects of life can be affected if large-scale damage occurs in an urban area, which results in not being able to travel [1].

For the development of maintenance works, it is first necessary to know the pavement conditions, based on correct inspection and monitoring processes of the road [2]. Roughness is one of the most relevant functional indexes and corresponds to irregularities in the pavement surface, affecting service quality. To quantify this factor, the international roughness index (IRI) is used as a statistical indicator of pavement irregularities and presents a unique scale of values for evaluation. There are different equipment and methods to calculate the IRI, which are classified into four classes. The class is related to the accuracy of the measurements; therefore, a class 1 method has higher accuracy, and a class 4 method has a lower accuracy [3].

The measurements are obtained based on the determination of the longitudinal profile of the road. For this, and as allowed by the four classes, there is different equipment. This is, for example, laser equipment (class 1) that achieves high levels of accuracy in the results; however, it is not widely used due to the high costs of the equipment and its maintenance, the workers' training. On the other hand, standardized manual methods such as the MERLIN equipment (class 3) provide reliable 
and internationally accepted results, whose execution times are much longer than lasers but with significantly lower costs.

The massive field of road inspection and maintenance standardly relies on tools and methodologies based on ancient concepts. This is not to say that they provide poor results, but that the modernization of these methodologies is imminent and must be made to meet today's state-of-the-art. The application of new technologies that are beginning to be implemented in the field of infrastructure construction and maintenance, as such, is increasingly noticeable.

This research seeks to generate new knowledge regarding the use of unmanned aerial vehicles (UAVs) and their direct applicability in road design, management, and maintenance.

The objective of this research is to reduce working time, human effort, and monetary costs, to be replaced by computational work, which through the technique of photogrammetry and support from 3D model generation software, seeks to install a new concept of work in the field of road inspection and maintenance. Using virtual scenarios, one will seek to obtain the same data or indexes obtained in situ. UAVs were used in conjunction with cameras and GPS for image collection and geo-spatial information. These tools allow us to reduce inspection time in road maintenance and data collection. These data are collected in image format and processed using software based on photogrammetry algorithms, allowing to obtain a virtual reconstruction of the scenario that was captured. The modeled scenario corresponds to a road with a certain resolution that makes it possible to accurately represent the surface of the asphalt layer and apply methods to extract information necessary for the calculation of the IRI.

\section{Materials and Methods}

\subsection{Research Methodology}

For the development of this research, the Design Science Research Methodology (DSRM) was used to show the entire process of justification, development, and testing [4]. In addition, tools and activities were added to expand the research carried out. In general, the research methodology is organized in five stages: (1) identification of observed problems and motivations; (2) the objectives of a potential solution; (3) design and development; (4) demonstration; and (5) evaluation. The activities and research tools that describe the scenario for each stage are specified below. Figure 1 shows a diagram of the research methodology.

The first stage identified the problems associated with current road inspection methodologies, maintenance, and analysis, which use time-consuming and resource-intensive equipment and strategies. The proposed method should reduce the time spent collecting the required data or obtaining the same data and reduces associated costs. To identify current tools to achieve the above requirements, a literature review was carried out, based on Web of Science search engines, using keywords: photogrammetry, road analysis, and Structure from Motion (SfM). The use of Scopus and related technical repositories allowed collecting articles emanating from congresses related to innovation in engineering and geomatics, in addition to referring to various research documents published in the last 15 years, to define activities, processes, problems, tools, capabilities, and equipment that will be essential in continuing the research. Once the necessary elements are recognized, a primary objective is defined, satisfying a potential solution. For this case study, the extraction of information from the exploitation of virtual models created using 3D reconstruction is defined by applying algorithms based on photogrammetry techniques and Structure from Motion (SfM), flight planning for UAVs, and capture of photographs to build the virtual scenario that will be able to provide relevant information in the analysis of roads and in obtaining a longitudinal profile associated with it.

In the third stage, the proposed methodology was designed and developed based on the knowledge and tools obtained from the literature review. This consisted of defining techniques and planning flight aspects for UAVs, techniques for accurate photo capture, learning, and application of virtual reconstruction software based on SfM algorithms and specialized software application for model 
analysis. Subsequently, the activities that lead to obtaining the longitudinal profile associated with the path are defined to obtain indexes and characteristics related to the roughness and deterioration that the route possesses.

The proposed method was implemented in the fourth stage; parameters and flight conditions for the UAV team were established; camera focus considerations and storage capacity and energy expenditure were estimated. The photographic records were uploaded to the Context Capture 3D modeling software, and the result was exported to a specialized analytics software called Power GEOPAK, which belongs to the same Bentley Inc. product line. The longitudinal profile of the path is obtained and used to calculate the IRI through existing techniques and proposed simulations.

In the last stage, a comparative analysis is carried out between the IRI values obtained in the study with the values of the official IRI certificate provided by the state road authority, which dates from the time the road was put into operation. Finally, considerations and recommendations are established to apply the method to be used in future work.

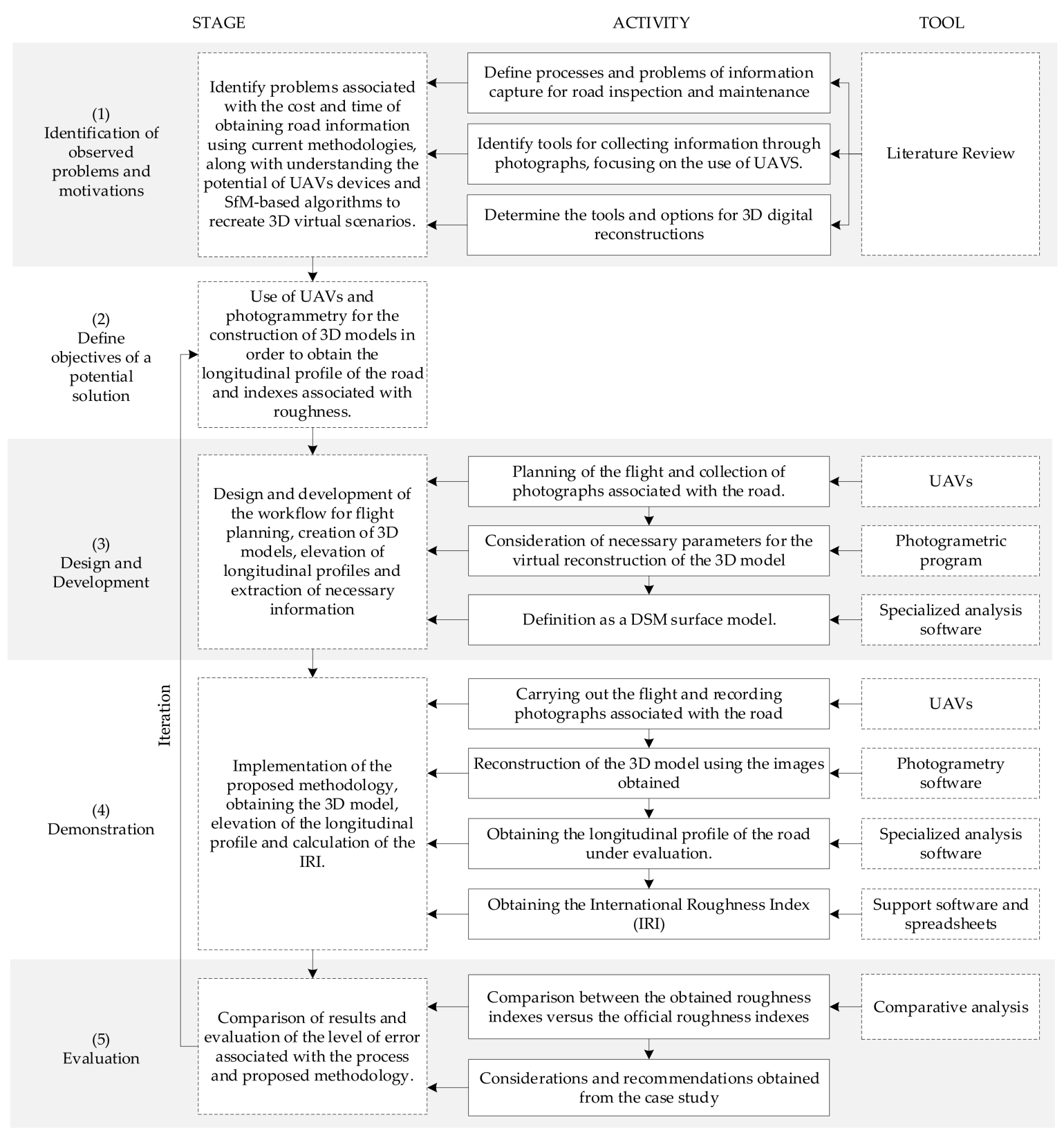

Figure 1. Research Methodology. 


\subsection{Background}

Transport infrastructure is essential in the development of a country. If it is kept in a state suitable for your usage needs, it makes an important contribution to the community's progress. Therefore, it is important to carry out appropriate evaluations to keep roads in optimal service conditions [5]. A continuous and appropriate process of monitoring the state of the infrastructure is essential. Generally speaking, the various activities' planning is based on the required frequency of structural measurements and the verification of the pavement's functional indexes. In particular, surface conditions should be properly monitored, particularly in road condition detection, identification, and classification [2].

Among the most relevant functional indexes is the index of roughness, defined as irregularities on the pavement surface that negatively affect the vehicle's quality of handling, safety, and integrity. It includes variations in the surface resulting from oscillations in elevation, which translates into vibrations for vehicles. Different vibrations are associated with different wavelengths, from slow oscillating motions produced by long wavelengths to rapid vibrations produced by short wavelengths [6]. To quantify the level of roughness presented on the pavement, the IRI is a statistical indicator of the pavement surface's irregularities. A single scale of values for the measurement of surface regularity of roads, which can be used by the vast majority of auscultation devices that exist today, is presented.

\subsubsection{Data Collection Technology}

The World Bank presents in edition No. 46 standards to measure the roughness of roads in use around the world [7]. Four classes are defined according to the reliability measure of the IRI, which are affected by equipment calibration requirements and the accuracy associated with their use. (1) Class 1 represents the highest precision standards for measuring the IRI, which equals a longitudinal profile with $0.5 \mathrm{~mm}$ precision in the vertical dimension as the basis for measurement. (2) Class 2 includes all other methods in which a longitudinal profile is required as the basis for IRI measurement; however, these results do not meet the accuracy conditions set for Class 1. (3) Class 3 includes measurement instruments that require the mathematical calculation to obtain the result. (4) Class 4 refers to subjective estimates of the value of the IRI, such as visual inspections [7,8]. A precise representation of the longitudinal profile is important, which is defined as an imaginary two-dimensional line that represents the surface along the path, plots the elevation of the surface, and is used to define the degree of design, to know roughness and the degree of deterioration, among other aspects [6]. This can be obtained using static or dynamic profilometers. The use of static profilometers consists of making measurements spaced in constant intervals; thus, it is necessary to define the distance between each measurement [9].

Once the longitudinal profile of the route is obtained, it is subjected to a procedure that allows the evaluation of the roughness of the road. For this purpose, some simulations record the characteristics associated with the road, based on vertical displacements induced to a standard vehicle, called the Quarter Car Model, which consists of a damped mass connected to a cushioned mass through a spring and a linear damper, in addition to representing the tire with another linear damper. In other words, the Quarter Car Model is defined as a set of inertial masses, springs, and damping systems that interact with the longitudinal profile of the road and whose resolution leads us to measure the accumulated vertical movements resulting from the irregularity that the road possesses. The dynamic equations presented in the model form a system of equations that use the longitudinal profile of the path as input data [10]. The vertical movement of the axis relative to the suspended mass is calculated and accumulated; thus, obtaining a value in units of $\mathrm{m} / \mathrm{km}$, which corresponds to the final value associated with the IRI [11]. This model simulates a vehicle's response when driving on the road at $80 \mathrm{~km} / \mathrm{h}$, and therefore allows us to consider factors such as safety, comfort, and cost of the use of vehicles [12]. For new roads, the IRI value fluctuates between 1.0 and $2.5(\mathrm{~m} / \mathrm{km})$, and then reflect an increase of such values as the path is used [13].

Laser scanning equipment placed on the front of a van is the standard instrumentation for IRI measurement; this equipment is in the precision Class 1 category. The roughness index calculation is performed using built-in software that allows processing and analyzing the path profile independently 
of the measurement and can be used at any time after measuring roughness in the pavement [13]. The laser equipment is positioned pointing towards the ground, where the beam is reflected and returns to the sensor where it was emitted to calculate the distance traveled between the equipment and the pavement. As a result, you get a dense point cloud that accurately replicates the surface. However, it only represents a narrow road area and is an expensive procedure [1].

On the other hand, there are cheaper alternatives that consider the use of mechanically operating equipment. To do this, the Transport and Road Research Laboratory (TRRL) developed the Machine for Evaluating Roughness (MERLIN) roughness meter, based on the principle of static profilometer to obtain a low-cost, easy-to-use, and simple analysis method with reliable results [14]. This equipment belongs to the precision Class 3 defined by the World Bank, which allows obtaining the IRI through mathematical correlations [7]. The operation of the equipment is based on the concept of using the distribution of surface deviations from an imaginary average string. It has also been defined that it is necessary to measure 200 deviations from the average string consecutively along the track and consider a constant interval between each consecutive measurement. For these conditions, it is required that the more roughness of the surface, the greater the variability of the displacements. By defining the histogram of the frequency distribution of the 200 measurements, it is possible to measure the dispersion of deviations and correlate it with the standard scale of IRI roughness. The statistical parameter that sets the dispersion's magnitude is the range of the " $\mathrm{D}$ " sample, determined after a $10 \%$ purge of the measurements [14]. The MERLIN equipment is characterized by the low cost of operation, ease of implementation, and use. However, the time it takes to perform the measurements is much longer than the time required by the laser profilometer.

New technologies have now emerged for the engineering and construction industry, especially in road engineering, where the main challenge of projects is associated with the great distances they cover. UAVs provide opportunities to improve productivity in inspection processes, increasingly being used in various fields, such as defense, agriculture, construction, among others. A UAV consist mainly of the aircraft, the control system, and electronic and radio equipment [15]. UAVs are useful platforms for collecting information, whether it be through sensors, cameras, or other equipment that can be added to the vehicle payload. They allow you to remotely inspect tasks that are currently carried out manually [16]. However, there are considerations to consider when using UAVs, including weather conditions, where wind and rain are determining factors, and the flight time associated with battery life [17,18].

The use of UAVs is feasible in the construction industry, and it will be the camera alongside the GPS that is responsible for collecting the necessary spatial information. The interest in the potential for various applications such as road inspection and road-related parameters has increased in many countries [19]. The image collection process is not random and must meet certain criteria which are evidenced.

Registered images should consider perpendicular orientation to the ground (Nadir) in addition to images with an oblique orientation that allows for observation of side parts of objects or surfaces that have elevation. Images will be used for viewing, identifying objects, and virtual 3D mappings [20]. This technical method has been widely used for the construction of 3D models of structures and Smart City. Additionally, the method has been applied to explore the potential use for electrical transmission lines, 3D analysis of the behavior of slopes, and 3D mappings in areas of natural disasters, obtaining good and reliable results [21]. However, 3D modeling with the use of oblique photographic techniques is rarely used in road engineering measurements. Nevertheless, this technique can assist in the planning of road design, its construction, maintenance [22].

A flight plan must be considered before starting data logging. It has to contemplate the proper translation between images [23]. The creation of 3D models requires a set of images that must be obtained, considering vertical and horizontal overlaps; the balance between vertical and horizontal overlap allows obtaining optimal results $[18,22]$. It will be necessary to set flight parameters to build 3D virtual scenarios that allow for an accurate representation of reality [24,25]. Therefore, it is important to consider some variables that condition the quality of the model obtained and influence the accuracy of the information collected. The main ones are the focal length of the camera used, the GSD (ground sample distance), 
and the MTF (modulation transfer function) [26]. In [23] and [27] it was concluded that the GSD should be taken into consideration when planning an information-gathering flight; In [28] it was concluded that the sharper images produce a higher quality point cloud, so the camera resolution must be considered, and sharpness can be measured through the MTF. The three variables mentioned above are defined below: (a) The focal length corresponds to the distance from the rear node to the point where the ray of light enters the lens to form a sharp image [29]. (b) GSD corresponds to the distance measured between two contiguous pixel centers that make up the surveyed surface; higher GSD values mean more diffused images [30]. (c) MTF corresponds to a Fourier transformation applied to sharpness measurement in images recorded by a digital camera [31]. Regarding the flight speed, this parameter is mainly related to the overlap required for the project and at a higher speed of flight, the speed of the photo shot should be higher. For general photogrammetry applications and overlap requirements of $80 \%$ longitudinal and transverse, the flight speeds should not exceed $5 \mathrm{~m} / \mathrm{s}$ in fast shooting mode [24].

\subsubsection{Data Production Technology}

Photogrammetry is the art, science, and technology used to obtain reliable information about physical objects and the environment through the process of engraving, measuring, and interpreting photographic images, energy patterns, and other phenomena [32]. The most widespread of its possible branches are aerial photogrammetry, which, from aerial photographs taken under meteorological and geometric conditions, allows us to draw plans and maps of large areas with precision and agility. In the case of urban areas, the limit drops considerably. However, it all depends on the accuracy and characteristics of the terrain in question [33]. The technique is based on the principle of stereoscopy to ensure that by viewing the terrain through photographs, the relief of the field can be reproduced. Two mathematical conditions must be met to make a 3D reconstruction of objects obtained in 2D images: collinearity and coplanarity. (1) The first condition refers to the linear relationship between any point in the actual space, the perspective of the center of the camera, and the same point (now a pixel) recreated in the image space. (2) The second condition refers to when any point (pixel) in the image space is combined with the same point (pixel) of other images that were collected considering slope; it defines that the points belong to the same plane [34].

One of the most commonly used techniques for 3D reconstruction from image processing is Structure from Motion (SfM). A SfM reconstruction uses images taken from different approaches or viewing angles [35]. In addition, lighting conditions, shadow changes, and missing data areas have been shown to impact the quality of 3D reconstruction negatively. Therefore, image acquisition planning is relevant and must be acquired in such a way that the conditions are constant, and the presence of moving shadows is minimized. The processing of the images begins with the detection of points which are characteristic of each image; these points are grouped by identifying common points in several different photographs. However, there are geometric distortions because images are taken from different perspectives, and it is necessary to identify points called key points. Since there is no guarantee that a key point will have a correspondence in another photograph, the next step is to apply algorithms to discard key points without a good match between them and images [36].

The scaling and georeferencing requirements for the target surface will vary depending on the used 3D model and should be considered before image acquisition. An object or surface can be completely $3 \mathrm{D}$ reconstructed without any scale or position of information, but ground control points (GPPs) must be provided to extract oriented and scaled data. The scale can be adjusted in the model by knowing the distance between two points in an image or the model. GPPs are transportable or stationary devices located in different locations within the area to be surveyed. They must be visible in the recorded images as they contain coordinate information to scale, rotate, triangular, and georeferenced the digital surface model (DSM) [32]. Theoretically, it is enough to place three GPPs in the area surveyed; however, it is recommended to position a greater amount to obtain more accurate results [37]. In recent years with the implementation of flights with GPS and inertial sensors, the number of GPPs needed to adjust a photogrammetric block has been greatly reduced correctly. GPS records the projection center 
coordinates of each photo and, together with the camera, works independently by obtaining data at different time intervals [33].

\subsection{Proposed Method for Collecting and Processing Information for IRI Calculation}

The proposed methods form a workflow that, when followed step by step, allows meeting specifications, requirements, and pre-flight considerations that allow for the correct acquisition of images, their computational processing, and virtual modeling, as well as the use of analysis tools in the model to obtain results that were defined in this research. It is divided into four general stages that, at the same time, contain their considerations or parameters that must be measured or defined. (1) Stage 1 corresponds to the definition of flight strategy, its characteristics, prior considerations, and sharp image collection, (2) is the processing of the information collected using virtual modeling software and SfM algorithms to achieve a virtual replica of the path being evaluated, (3) is the use of analysis tools that are incorporated into the software where the model is imported once created, (4) corresponds to the application of simulators that obtain results from the IRI considering as input data, and to the longitudinal profile that was extracted from the virtual surface. Figure 2 shows the proposed workflow.

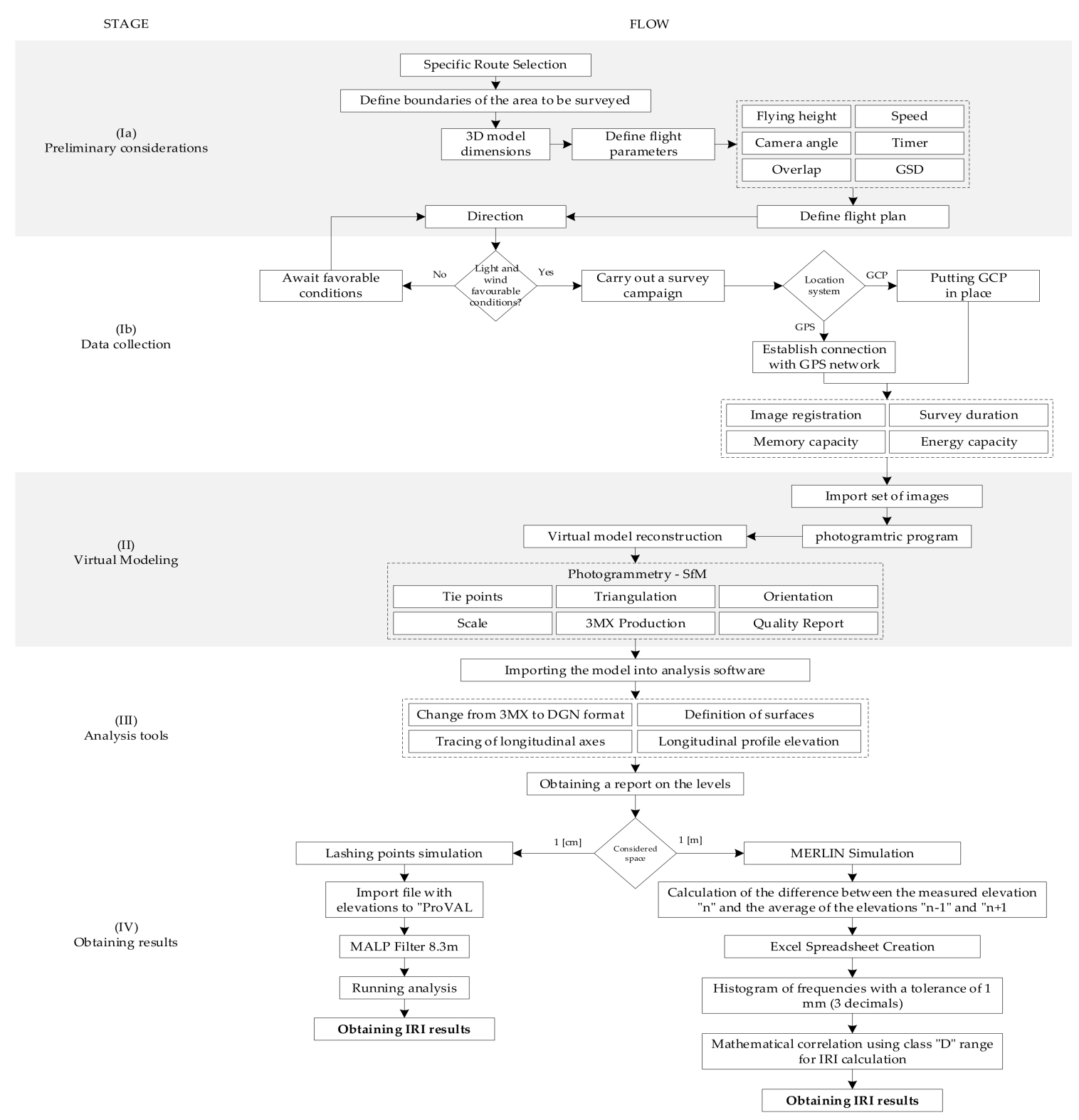

Figure 2. Proposed workflow. 


\subsubsection{Data Collection}

The first step at this stage is to define the path you intend to model. Limits must be set for the length and width of the area to be surveyed, as this has a direct impact on the dimensions of the model and, therefore, on the available computational processing capacity. There are six flight parameters to consider: (1) height or height range covered by the UAV team; (2) flight speed, which should be constant while capturing the image; (3) setting a timer for the camera, automating the recording of images achieve continuity between them; (4) overlap between the captured images; (5) camera focus or angle, which should range from 0 degrees (Nadir) to 45 degrees (oblique images); (6) calculating the GSD parameter as it allows us to know the width and length in meters that each image represents depending on the flight height and the intrinsic characteristics of the camera used, and this parameter allows us to know the dimensions that a pixel represents.

Concerning the definition of the flight plan, the direction used will be parallel to the longitudinal axis of the road in both directions. Weather conditions will affect the survey campaign, the presence of strong winds or rain are reasons to postpone the flight, as they affect the stability of the aircraft as well as the quality of the images. When conducting the campaign, it is important to know the available image storage capacity, in addition to the battery capacity of the UAV equipment, in order to avoid possible inconveniences during the flight exercise, such as reaching the memory limit or running out of power for the equipment. It is necessary to determine whether the positioning system to be used will be "manual" using well-defined ground control points (GCP) checkpoints within the area to be surveyed or will be "automatically" by connecting to the global GPS network system. Moreover, complete visualization of UAV equipment by the pilot must be ensured.

\subsubsection{Virtual Modeling}

In order to achieve 3D virtual reconstruction, the collected images must undergo computational processes that use algorithms based on photogrammetric techniques called Structure from Motion (SfM), which manage to represent digital surface models (DSMs). SfM algorithms allow you to merge recorded photos using computer vision techniques, which automatically defines pixels as tie points in photos that recognize common elements [22]. In this way, it generates a 3D representation based on 2D images. SfM-based algorithms adjust all recognized point packages in photos to minimize average quadratic error (RMSE) [38]. This optimization problem is known as Package Adjustment (Bundle Adjustment) [39].

Usually, GCP is applied to improve the model's accuracy; however, following the findings of [40], it is possible to obtain satisfactory results without GCP for similar applications in road projects. To verify a correct and reliable digital representation of the pavement, it is possible to perform a generated point cloud analysis (PC) using graphs that explain the quality of the reconstruction in terms of resolution and uncertainty of the points' location. DSM models will be useful for surface analysis, in this case, of pavement. Once the model is created, it is possible to extract longitudinal profiles representing the different axes considered in traditional methods when assessing the roughness of the road.

\subsubsection{Extracting Information from the Model}

This stage corresponds to the importation procedure of the newly created virtual model to the specialized analysis software. This allows for the use of surface definition tools in order to continue the polygon meshing created by the virtual image reconstruction engine, after which longitudinal axis plotting tools are used in a 2D representation of the model, where the drawn axis is able to capture the height information of each point on the surface. The height information is represented in an elevation view of the longitudinal profile that the modeled path possesses. In addition, it allows the user to define the spacing between dimensions that the profile will have, thus giving the ability to obtain "dense" profiles with a small spacing between dimensions or "light" profiles with greater spacing 
between them. Then, it is possible to obtain the longitudinal profile report, which contains the height versus spacing information that dimensions have, which is used to calculate the IRI.

\subsubsection{Data Processing}

For obtaining the IRI, there are various procedures or simulations; as far as this research is concerned, it is proposed to use two methods: (1) to obtain the IRI through of the quarter car model considering the longitudinal profile with a spacing between the level equal to $1 \mathrm{~cm}$; and (2) the use of statistical techniques and correlations using a re-creation of the low-cost instrument called MERLIN, which considers 1-m spacing between dimensions.

For the series of spaced data every $1 \mathrm{~cm}$, it is almost mandatory to filter the sequence of data points that make up the profile. The use of ProVAL software is considered for filtering and analysis of the longitudinal profile obtained. Filtering corresponds to a mathematical procedure that transforms a series of data into a new data series. A simple filter commonly used in longitudinal profile analysis is the moving average filter, which replaces each point in the profile with a new point obtained considering an average of adjacent points, producing a smoothing effect [3]. The value of the moving average low-pass (MALP) short wave filter proposed in this research is $8.3 \mathrm{~m}$. Finally, the analysis is run, and the value of IRI is achieved.

On the other hand, when defining a profile with 1-m spacing between dimensions, the simulation proceeds to consider the MERLIN method. To do this, you must calculate the difference between the actual dimension measured " $n$ " and the average of dimensions " $n-1$ " and " $n+1$ ", which define the "average string". Calculated differences must be recorded in a separate column to make a histogram that reveals the number of times a certain deformation value is presented. To do this, a tolerance of $1 \mathrm{~mm}$ is taken into consideration, or 3 decimal places are used. Once the histogram is created, the class range must be obtained, multiplied by a factor of 5 to transform it into millimeter units. This factor corresponds to the length of each box that has the MERLIN method form template that must be filled with the deformations when using the MERLIN equipment. This is how the class range " $\mathrm{D}$ " is obtained, which, before being entered into the correlation equation established for this class 3 equipment, $10 \%$ of the data located at the ends of the histogram are eliminated. That is if the measurement corresponds to $200 \mathrm{~m}$, it is the first and last 10 data points that must be deleted in order to give greater preponderance to the deformations that are repeated more times; below is the correlation equation for the calculation of IRI.

$$
\text { For IRI }<2.4, I R I=0.0485 * D(\mathrm{~m} / \mathrm{km})
$$

The equation shown corresponds to the correlation used for the calculation of the IRI, considering the use of MERLIN equipment for new or semi-new paths. Finally, the value for the IRI is obtained.

\subsection{Experiment to obtain the IRI}

Figure 3 represents where the survey was conducted. The experiment carried out is detailed below, which aims to obtain IRI values that match reality. This experiment looked to reproduce the proposed methods with the main goal of obtaining IRI values on working routes. Adjacent to the main route, there is a deflection to an area used as a viewpoint and a parking lot. This was defined as the area to be surveyed, so vehicle traffic for this experiment was not a potential parameter or element to consider. Furthermore, there is a low amount of vegetation on the sides of the viewpoint, which facilitates the flyover. IRI values are in the order of $2.5 \mathrm{~mm} / \mathrm{m}$ for new roads and $12 \mathrm{~mm} / \mathrm{m}$ for roads with greater use and deterioration. In order to capture this range of deformations, a GSD $<0.5 \mathrm{~cm} / \mathrm{px}$ is necessary [3]. This is achieved, for the drone used at heights less than $10 \mathrm{~m}$. For this experiment, the range of heights considered is between 1 to $10 \mathrm{~m}$, where higher-altitude photographs use Nadir approaches to contextualize the environment to be mapped. In contrast, lower-rise ones consider obliqueness of approximately 45 degrees to capture greater details on the pavement surface. 


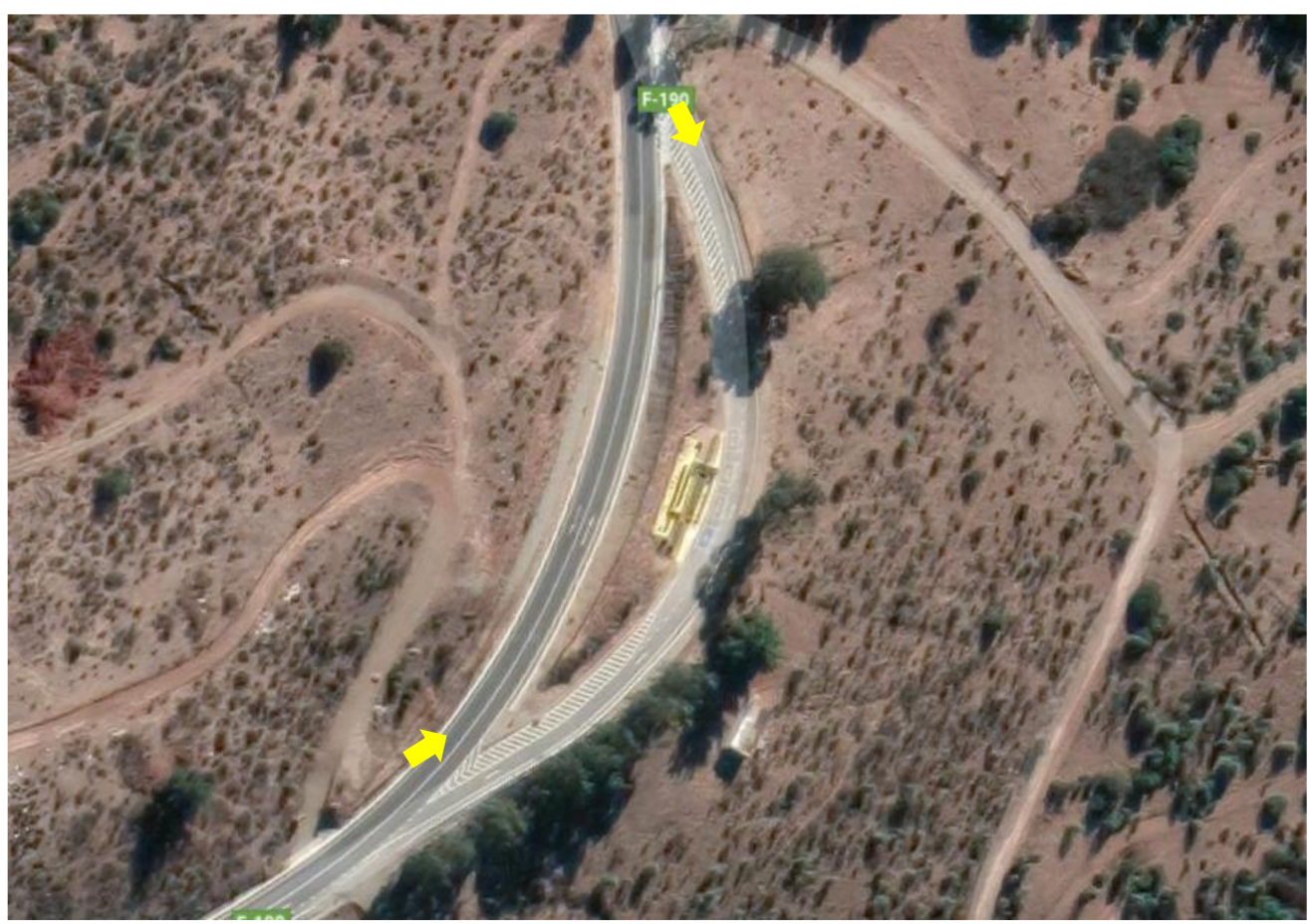

Figure 3. Analyzed area Mirador Ruta F-190, Source: Google Earth.

The sector evaluated has a left turn and a continuous downward slope of $6 \%$, where the difference in dimensions between the start and end of the sector surveyed is $8 \mathrm{~m}$, the total length of the stretch is $170 \mathrm{~m}$. It should be noted that the weather conditions during the survey were favorable in terms of luminosity and wind speed.

The flight plan executed in the first instance corresponded to a flyover at $10 \mathrm{~m} \mathrm{high}$, where it a speed of $1.5 \mathrm{~m} / \mathrm{s}$ was adopted in order to maintain a minimum overlap between photos of $80 \%$, the camera timer was set for obtaining photographs every $2 \mathrm{~s}$, in addition to a Nadir approach. The piloting of the UAV was manual and moved along the central axis of the road in both directions.

In a second instance, heights of between 1 and $3 \mathrm{~m}$ with oblique focus were considered by 45 degrees, the flight speed was reduced to $1 \mathrm{~m} / \mathrm{s}$, and the timer between photographic records was also reduced from 2 to $1 \mathrm{~s}$. Further, to the photographs recorded along the direction of the road, photographs were added, which were taken perpendicular to the longitudinal axis in order to provide higher quality in the generated virtual model. A total of 734 photographs were recorded, and the imaging procedure took about $30 \mathrm{~min}$.

For this experiment, the use of GCP was not considered since the UAV equipment had integrated satellite location sensors granting automatic positioning of the model in the global GPS network. Once the set of images that were used to recreate the virtual scenario was obtained, the photographs were loaded into a program that can triangulate the positioning of the UAV equipment, using the metadata information provided by the satellite positioning sensors according to the direction and angle of focus that each image possessed, in order to build virtual 3D models using photogrammetric and SfM techniques. Specifically, the UAV equipment used for this information collection campaign is detailed in Table 1.

For the correct creation of a 3D model, it was necessary to meet certain computational requirements that allow obtaining higher quality results. The product of the long dimensions of the model is that a high-end processor is required, in conjunction with RAM capacity close to $32 \mathrm{~Gb}$ and a graphics card of at least $2 \mathrm{~Gb}$. The Bentley Context Capture software has been used, based on the conclusions of [41], where the lowest levels of error in 3D models have been found in this software, compared to Pix4D and Agisoft PhotoScan. The research considers the limitations of access to these two software, which is 
why no comparative tests have been done with them. The image set was loaded into the software where using SfM algorithms and photogrammetric techniques, it manages to recognize points that are in more than one image and thus, in conjunction with the respective GPS location that each image has, the information contained in each of them is triangulated to define the location in the model of each recognized mooring point. According to the positioning system adopted, the model was oriented in the global GPS network, in addition to being assigned a scale. Once the virtual model was successfully created, reports were obtained that quantify and diagnose the quality of the reconstruction. The format of the generated output file is $3 \mathrm{MX}$.

Table 1. Technical specifications unmanned aerial vehicles (UAV) equipment used.

\begin{tabular}{cc}
\hline UAV: & DJI Phantom 4 Pro+ \\
\hline Satellite positioning: & GPS/GLONASS \\
Max. Resistance Wind & $10 \mathrm{~m} / \mathrm{s}$ \\
Speed: & $1388 \mathrm{~g}$ \\
Weight: & $30 \mathrm{~min}$ \\
Max. time flight: & $20 \mathrm{MP}$ \\
Sensor: & FOV $84^{\circ} 8.8 \mathrm{~mm} / 24 \mathrm{~mm} \mathrm{f} / 28-\mathrm{f} / 11$ auto focus $1 \mathrm{~m}$ \\
Lens: & $8-1 / 2000 \mathrm{~s}$ \\
\hline Shutter Speed: & \\
\hline
\end{tabular}

After the virtual model was created, the 3MX file is imported using analysis software called Bentley power GEOPAK V8i to generate a 3D "seed file" in DGN format. Later, the model was modified so that it is recognized as a surface element. Then, from the 3D seed file, a 2D seed file is generated so that it is possible to interact with the previously generated surface so that by drawing a longitudinal axis over the path, that axis obtains information regarding the height of each point, thus achieving the longitudinal profile of the path. Subsequently, a report was exported, which contains a list with two columns, the first of which corresponds to the spacing considered and the second to each point's height.

To corroborate and compare the data obtained, an official certificate of testing No. 0778/19111 of IRI measurement was available by the Directorate of Roads of the Ministry of Public Works of Chile, carried out on the ROL F-190 route between kilometers 19,600 and 19,800. The equipment that was used to carry out this test was a MLP profilometer.

Two methodologies were used for the calculation of the IRI; the first is based on simulating the operation of the MERLIN equipment and its statistical logic to form a histogram containing the number of times a certain deformation value is presented in each one-meter interval. For this, it was considered to measure the difference between the dimensions obtained in the profile versus imaginary dimensions obtained by taking the average of the two adjacent dimensions consecutively along the track. For these conditions, the rougher the simulation, the greater the differences between the actual and the imaginary dimensions.

The second methodology is based on using a longitudinal profile that has one centimeter spacing between dimensions. The dimension report is imported into a computational program that allows you to simulate the Quarter Car Model on the profile entered and thus obtain the IRI based on the standards and parameters set by the FHWA/LTPP.

\section{Results and Discussion}

Once the photo set was uploaded and processed, the 3D virtual model was obtained, which corresponds to the virtual reconstruction performed using Bentley's Context Capture line of computer programs with cloud processing service (Bentley Cloud Service). Table 2 shows the flight parameters, Table 3 presents the setting model parameters, and Figure 4 shows the model generated in Context Capture. 
Table 2. UAV—Flight parameters.

\begin{tabular}{cc}
\hline Parameters & Value \\
\hline Flight height & $1-10 \mathrm{~m}$ \\
Flight speed & $1-1.5 \mathrm{~m} / \mathrm{s}$ \\
Minimum overlap (longitudinal/transversal) & $80 \% / 80 \%$ \\
Photo capture timer & $1-2 \mathrm{~s}$ \\
Camera angle & Nadir $-45^{\circ}$ \\
Maximum GSD considered & $0.26 \mathrm{~cm} / \mathrm{px}$ \\
\hline
\end{tabular}

Table 3. Setting model parameters.

\begin{tabular}{cc}
\hline Parameter & Value \\
\hline Number of photos uploaded & 734 \\
Number of photos used & 733 \\
Percentage of photos used & $99.9 \%$ \\
Processing time & $25 \mathrm{~min} 56 \mathrm{~s}$ \\
GSD & $1.93 \mathrm{~mm} / \mathrm{px}$ \\
Model scale & $1: 6$ \\
Image dimension & $4886 \times 3648 \mathrm{px}$ \\
Total Tie Points & 253,520 \\
Average Tie Points per image & 1519 \\
Average RMS error & $0.56 \mathrm{px}(1.08 \mathrm{~mm})$ \\
Minimum RMS error & $0.01 \mathrm{px}$ \\
Maximum RMS error & $1.83 \mathrm{px}$ \\
\hline
\end{tabular}

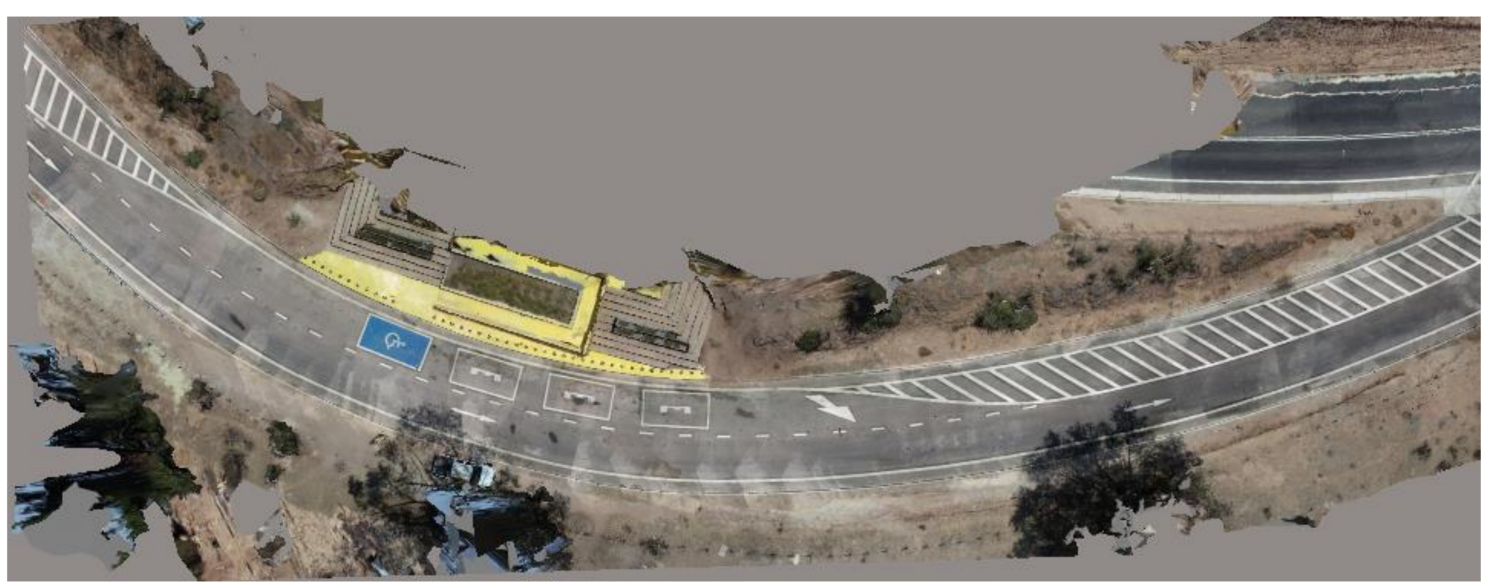

Figure 4. Virtual model "MIRADOR1" generated in Context Capture.

In total, 733 of the 734 images uploaded to the program were correctly calibrated, resulting in $99.9 \%$ of the images correctly calibrated, which is considered sufficient to believe that the image capture campaign was successful. The processing time for a model generation was 25 min 56 s. A GSD value equal to $1.93 \mathrm{~mm} /$ pixel is obtained, and the model scale is 1:6.

Regarding the number of "tie points" that were earned, on average, an amount of 1519 points per image was reached, obtaining a total of 253,520 mooring points in the model. Figure 5 shows the number of photos each mooring point considered for virtual reconstruction, where $Y X$ axes correspond to a plan view, ZX a cut view, and ZY an elevation view. Each color represents the number of photos that share the same mooring point is considered for virtual rebuilding. The minimum number of photos considered a mooring point was 3, while the maximum value reached 66 photos. The average number of photos considered per mooring point is four photos, and the vast majority are located in the area corresponding to the pavement. However, there is an area at the end of the road, where an appropriate density of mooring points was not observed. 


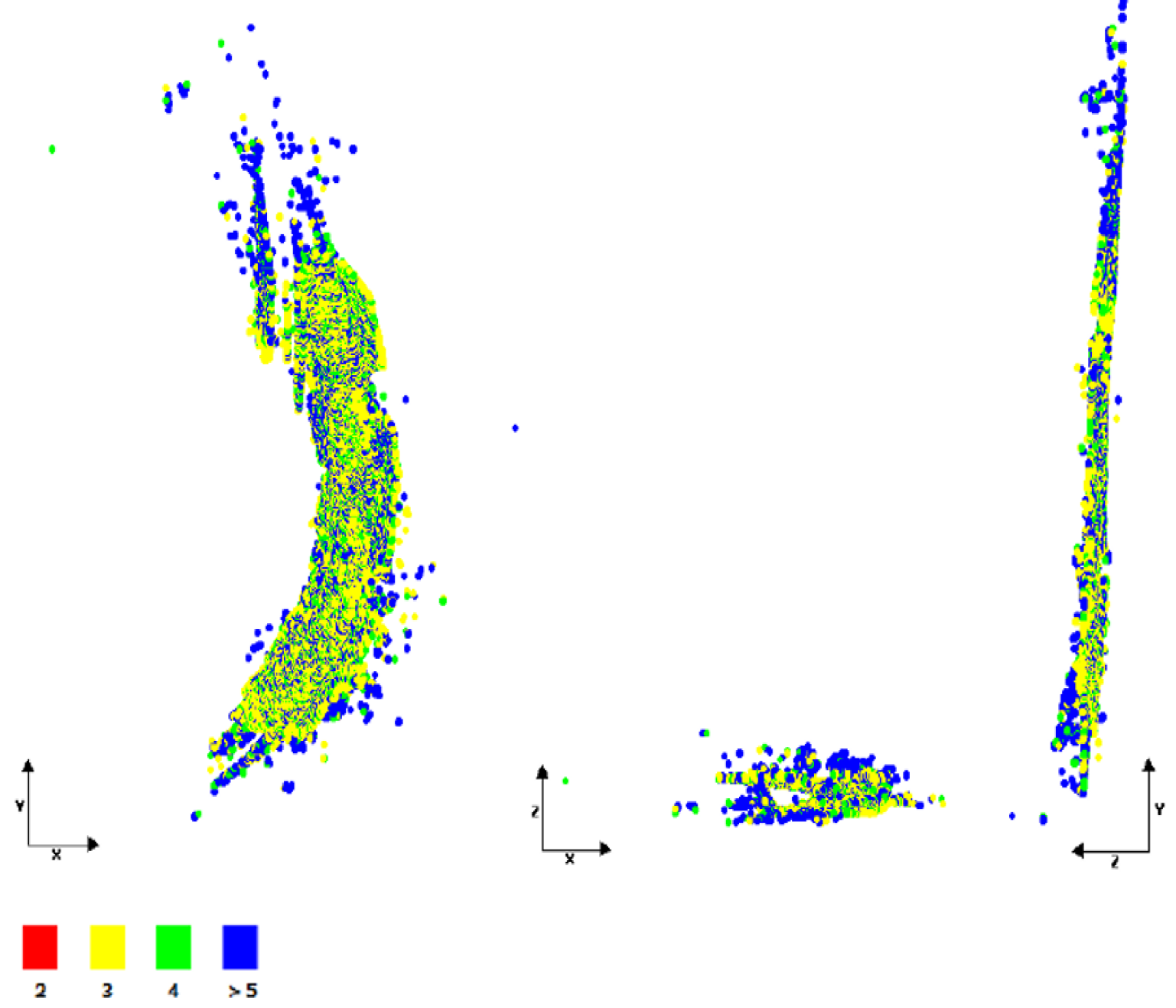

Figure 5. Number of photos that consider the same tie point [\#photos/point].

The graph shown below represents the root mean square (RMS) reprojection error calculated for the tie points generated in the 3D rebuild, where an average value of 0.56 pixels or $1.08 \mathrm{~mm}$ of error was reached. Figure 6 identifies each mooring point with its respective RMS value.

Figure 7 shows the distance between the UAV equipment's position obtained through the metadata and the position of the image calculated in the reconstruction. The arrows indicate the "gap" or distance between the metadata information and the calculated position of the image; all arrows start from the metadata position and end at the calculated position of the image. The shortest distance obtained was $0.31 \mathrm{~m}$, while the largest was $8.22 \mathrm{~m}$. The average distance reached a value of $2.43 \mathrm{~m}$, where the main distances occurred around the Z-axis, which corresponds to the elevation; the distances between metadata and image calculated in the $X Y$ plane are minimal. The results are related due to the lower accuracy that GPS equipment has concerning elevation.

The uncertainty of the position of the tie points is shown in Figure 8, represented with different colors according to the greater or lesser uncertainty that existed for each point.

It was observed that the lower uncertainty values for mooring points are close to $0 \mathrm{~m}$ in areas corresponding to the road itself, while the maximum values reach $0.76 \mathrm{~m}$. This aspect relates to the greater uncertainties in the areas that correspond to the edges or contours of the model, which is expected since the object to be reconstructed is the path and not the sectors or objects adjacent to it. Figure 9 shows the representation of each mooring point according to the resolution they have. 
Each color represents the resolution that mooring points have independently. Values are measured in meters/pixel units, where the minimum value reached a resolution of $0.0004 \mathrm{~m} /$ pixel, while the maximum value is $0.033 \mathrm{~m} /$ pixel. On average, a value of $0.002 \mathrm{~m} /$ pixel was reached. It is important to note that the higher resolution of the model is presented on the surface of the pavement, this is a product of the fact that the image collection campaign was focused on studying the route.

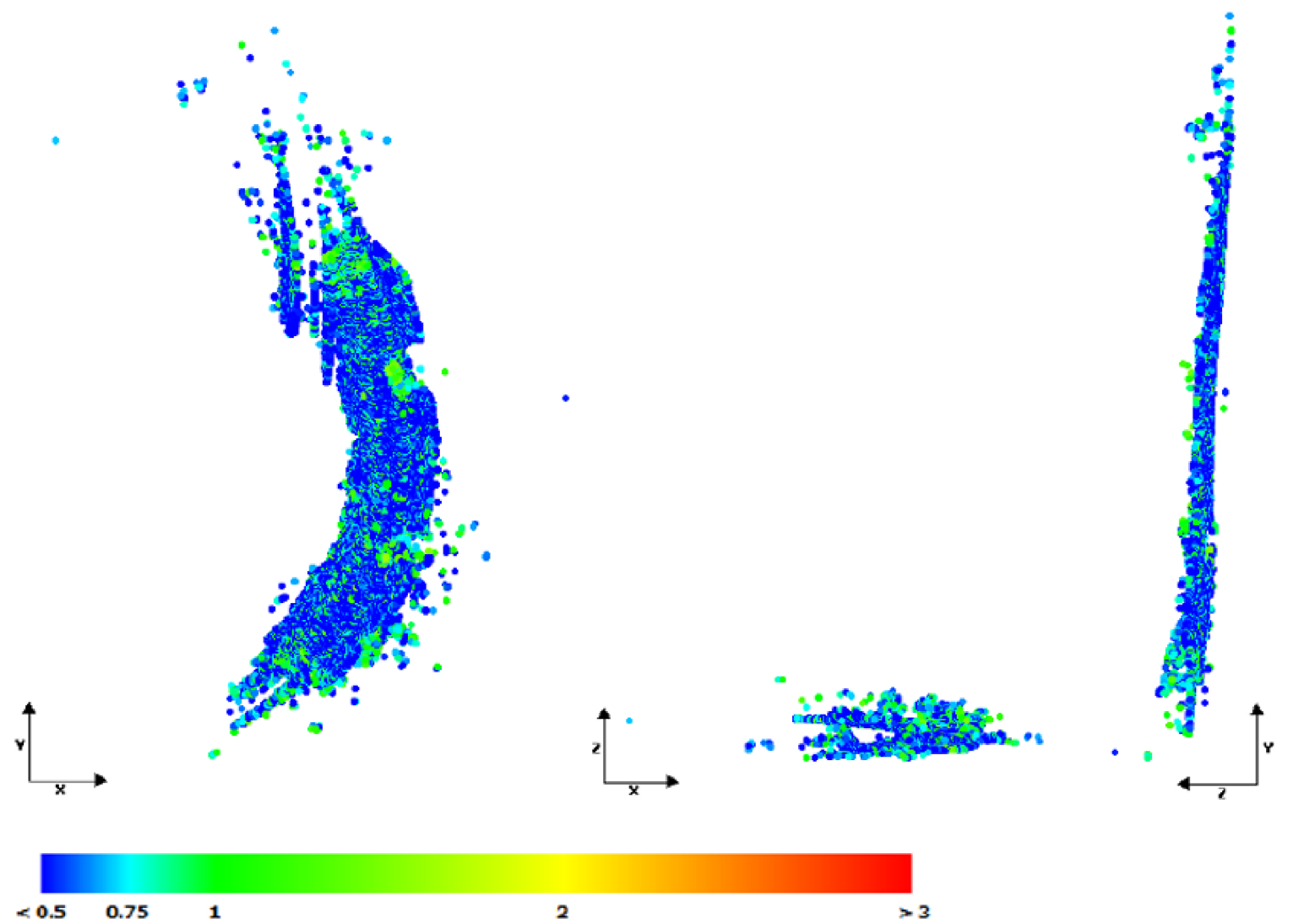

Figure 6. Reprojection error root mean square (RMS) (px).

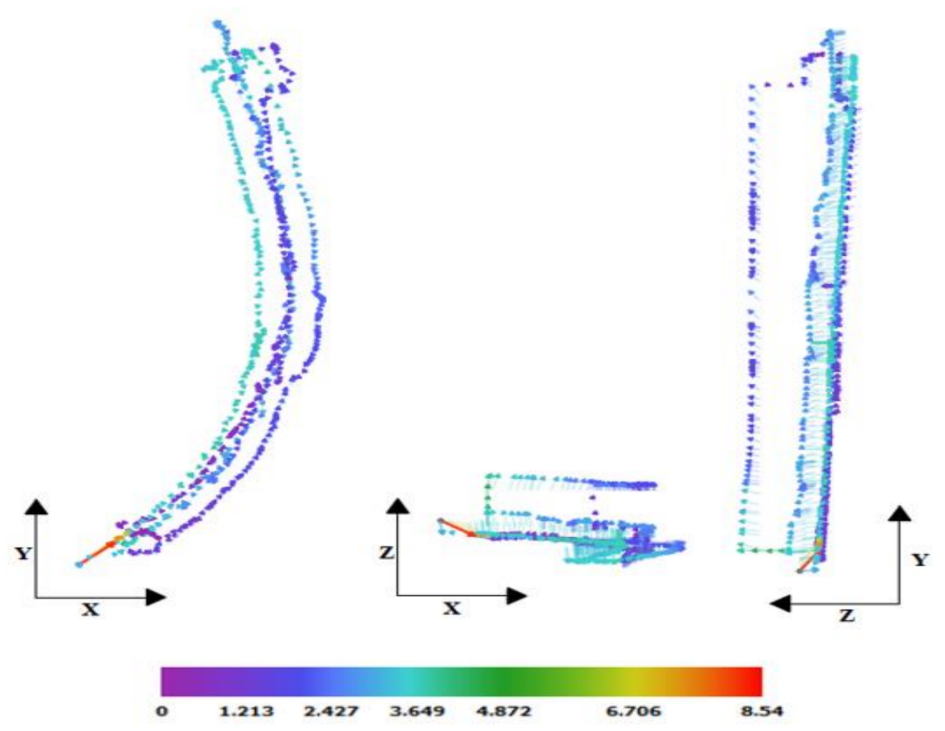

Figure 7. Distance between computed image and metadata $(\mathrm{m})$. 
The different graphs show the density of mooring points of the model in its different sectors, allowing to verify the accuracy of the virtual reconstruction process. The area corresponding to the road presented a high concentration of mooring points, which is also expected to be favorable for this case study. However, there are areas belonging to the road which have lower concentrations of mooring points, which means that the model in those areas is not able to accurately represent the surface. These areas correspond to the beginning and end of the path surveyed, that for the purpose of longitudinal profile analysis, were not considered. That is, a cut was made to the longitudinal profile at both ends to eliminate those areas with low-density mooring points.
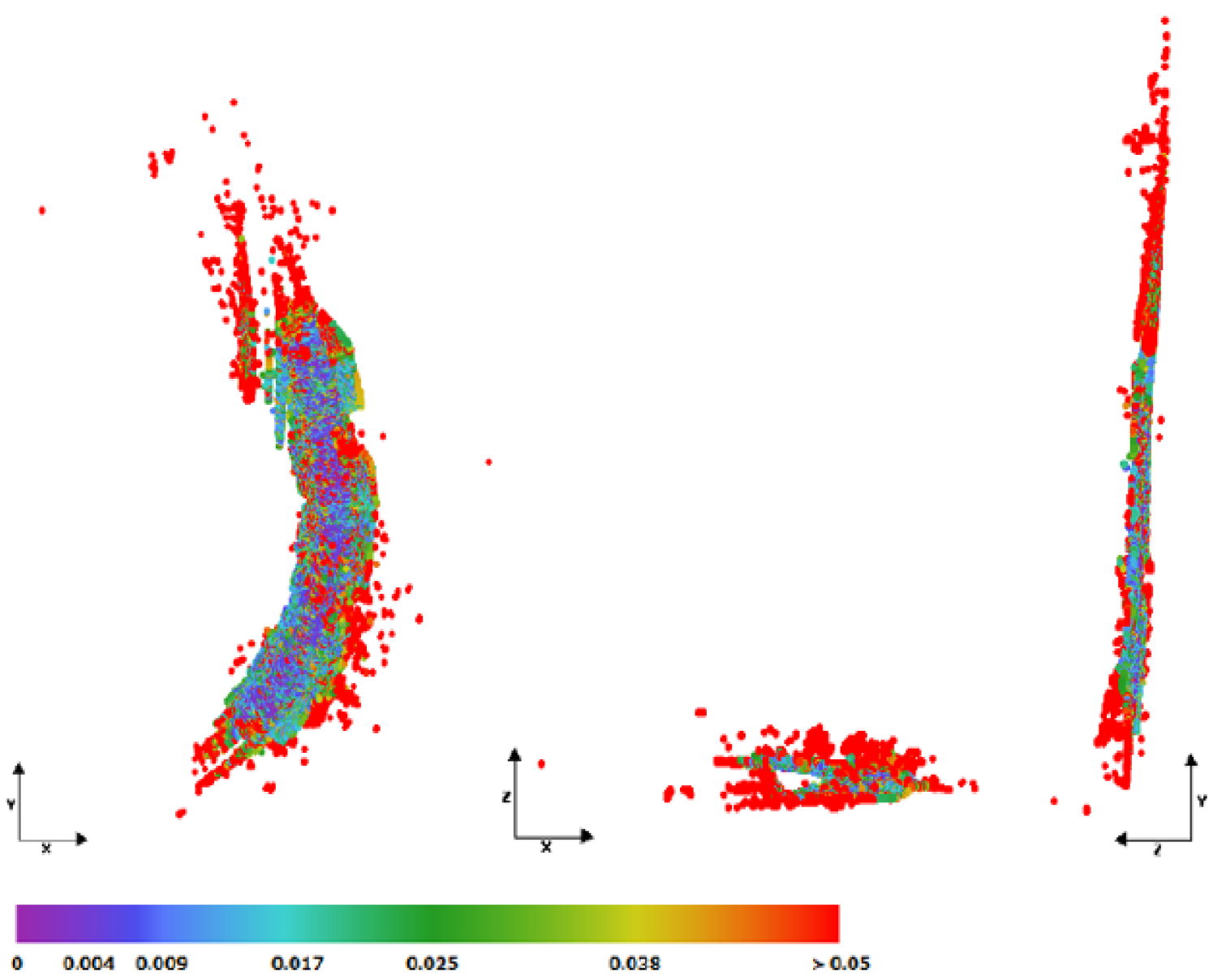

Figure 8. Uncertainty at tie points (m).

The 3D model is obtained in 3MX format, which is imported from BENTLEY's Power GEOPAK V8i computational program to change its format to DGN, in order to analyze, use and manipulate the information that the model has given its geometric characteristics. Once the format change was completed, the model was evaluated according to visual elements that allow a better understanding of its characteristics and the quality of the reconstruction. Figure 10 shows some display styles.

Thermal display styles are characterized by using color scales to represent the results, which is useful given their ease in interpreting them. Image (a) corresponds to thematic results of measurements on the slope; depending on the slope's increase, the coloration will change to warmer shades. It is useful in analyzing slopes adjacent to the route or for slopes of the road. A small slope was observed, which reaches a green hue representing approximately 45 degrees, while the path has cold hues belonging to the range 0-9 degrees of slope. Figure 10b represents the aspect angle of the UAV equipment relative to the model surface, where the color is derived from the aspect angle of the slope. This is a measure of the direction of the slope. Finally, in Figure 10c, the display style used corresponds 
to the variation of the warmth in the coloration according to the height that the element or sector of the model has, where warm colors represent areas of higher altitude. You can see that the road has a declining slope.

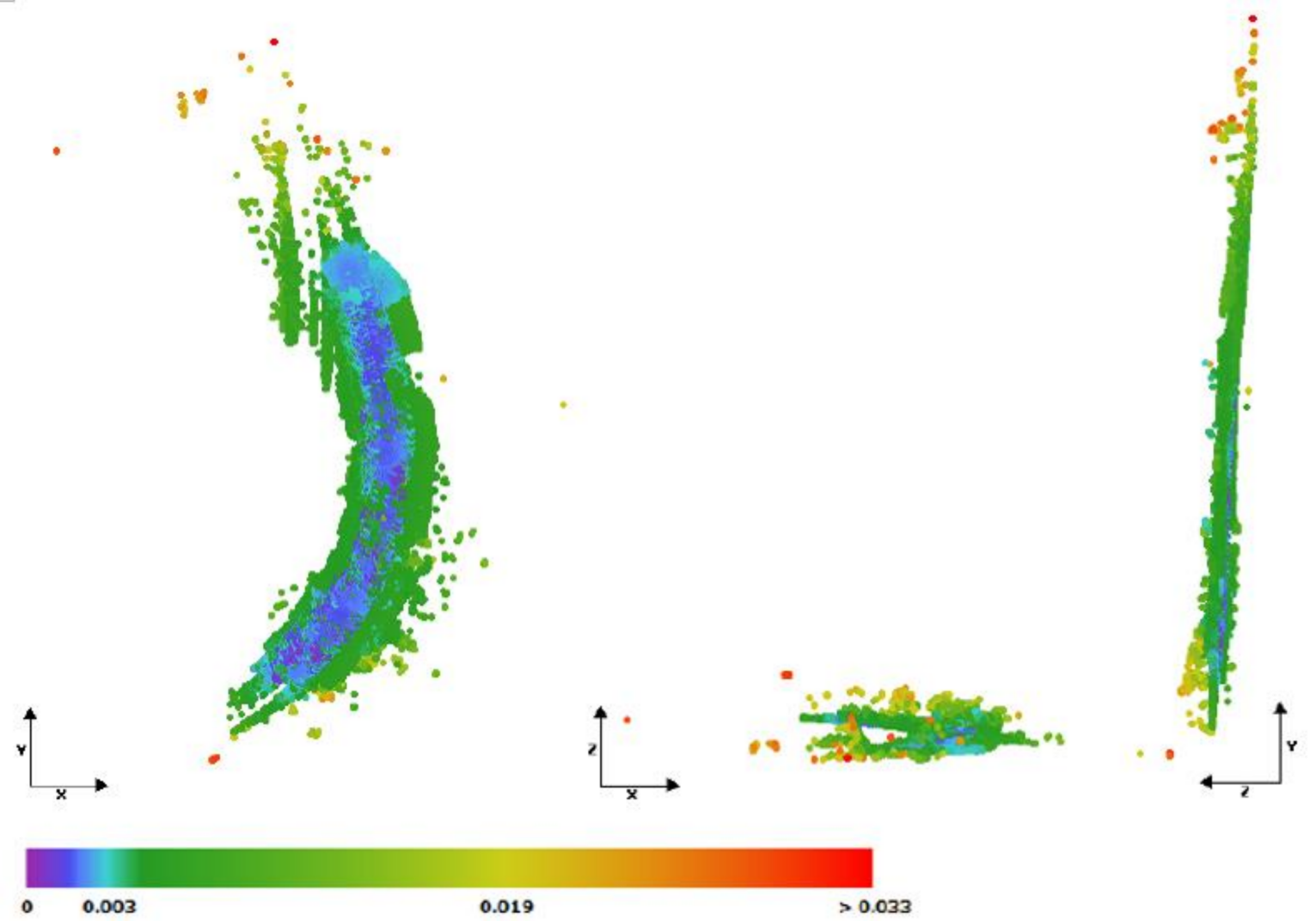

Figure 9. Resolution of tie points. Source: CC Report (m/px).

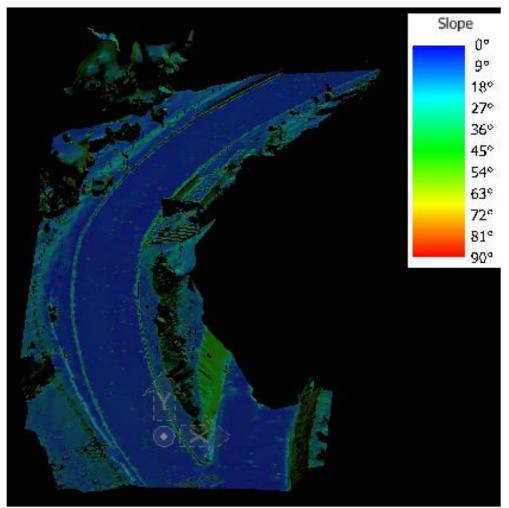

(a)

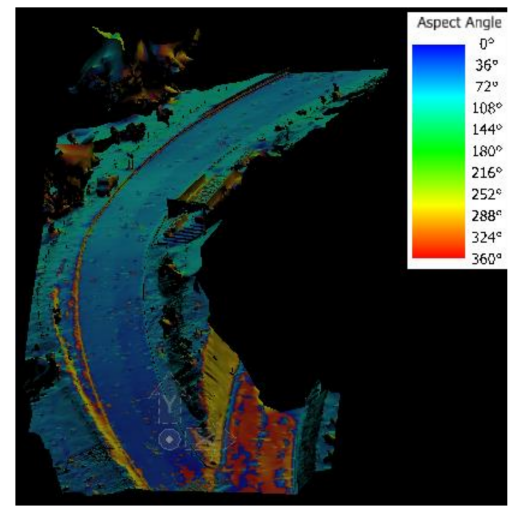

(b)

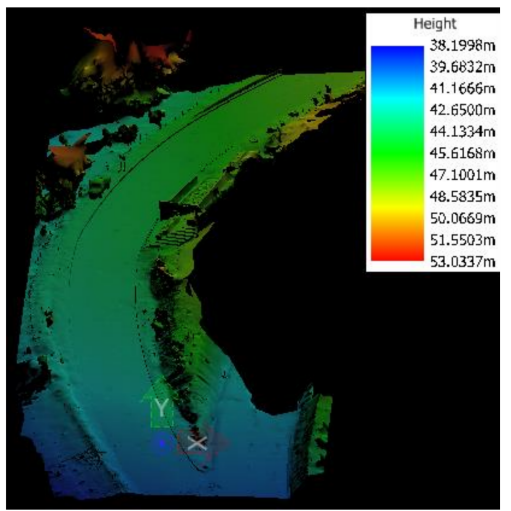

(c)

Figure 10. Display styles applied to model "MIRADOR1": (a) Road slope; (b) UAV angle relative to the model surface; and (c) Road height.

To reproduce the center axis on the path, the model was assigned surface properties. To this end, this property was modified in the pavement area, excluding some sectors of the model that have no relevance to modify as they do not contribute to the analysis. Figure 11 shows the area that was considered as a surface, which has a pink coloration. The ones that were decided to exclude are represented by white hue. 


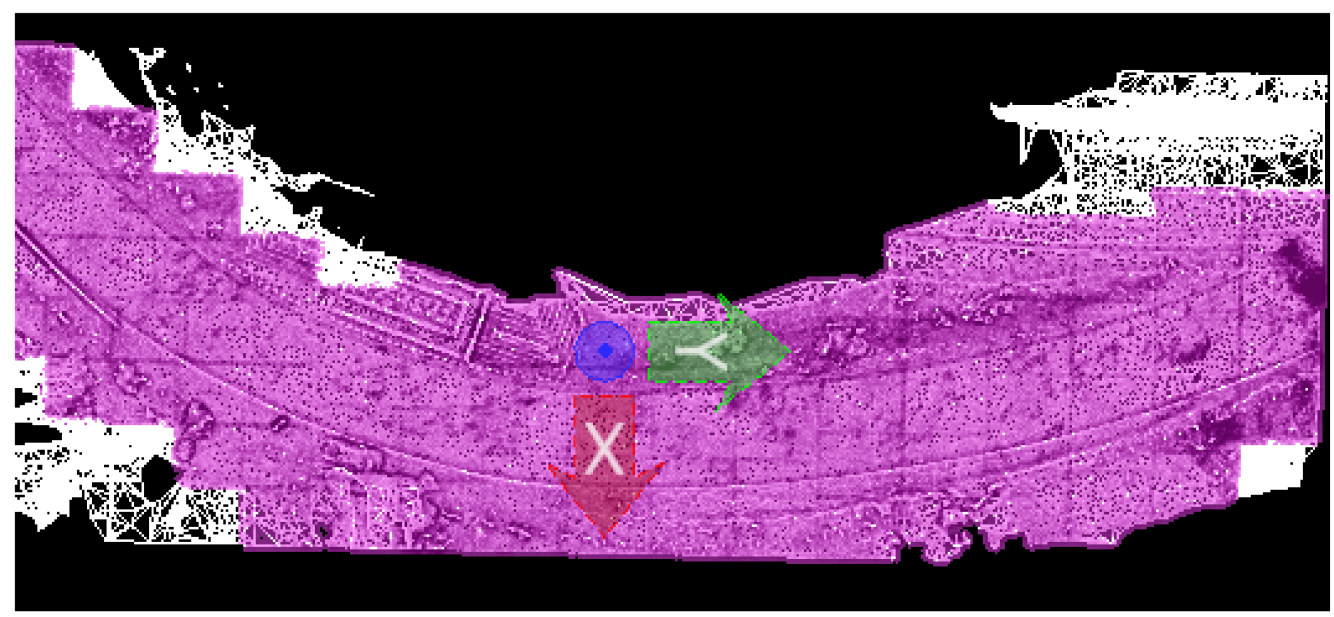

Figure 11. Surface mapping.

Figure 11 represents a plan view of the model. Once the surface feature was assigned, it was possible to use tools that allow you to plot longitudinal axes, raise longitudinal profiles, draw corridors, among other options related to analysis and drawing of paths. Figure 12 shows the longitudinal axes associated with the right girdle and left girdle of the road, respectively, and then the longitudinal profiles corresponding to each axis were obtained.

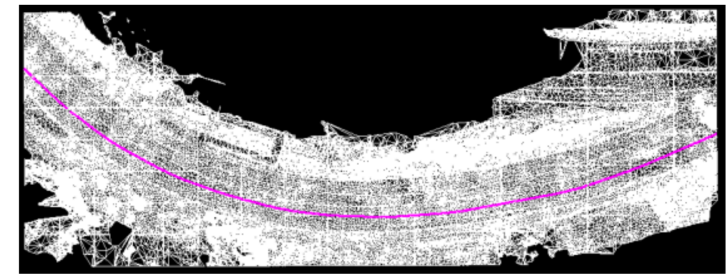

(a)

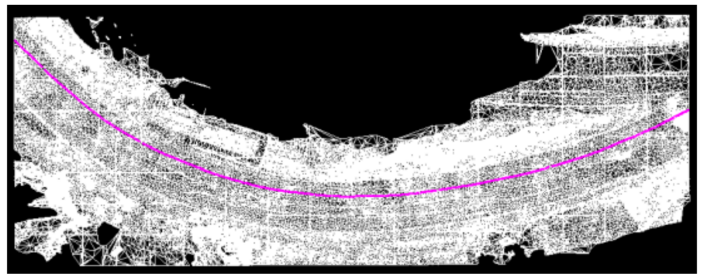

(b)

Figure 12. Longitudinal path of the right axis (a) and left axis (b).

Based on the axes drawn, the longitudinal profiles corresponding to each axis were obtained. A minimum spacing or interval of $1 \mathrm{~cm}$ was considered for each point corresponding to the profile elevation. Figure 13 shows the longitudinal profiles obtained.

In conjunction with the profiles, a report was obtained containing the list of dimensions and spacing associated with each of them. This report was used as input for the calculation of IRI.

Replicating the mathematical concept of the MERLIN team, an Excel spreadsheet was generated, which allows for the estimation of IRI values. To do this, 1-m spacing between dimensions was considered, given the geometric characteristics of the equipment. A histogram was built, and the sample range " $\mathrm{D}$ " was obtained and then used corresponding mathematical correlations for this class 3 profilometer.

The longitudinal profiles considered for the calculation of the IRI through the simulation of the Car Room were subjected to a filtering process in ProVAL. The moving average low-pass (MALP) filter was used for this purpose. A filter cut-off value was used for waves equal to or less than $8.3 \mathrm{~m}$. This filter seeks to smooth the longitudinal profile of the point-to-point model, taking into account the possible differences in height that could occur in the vicinity of the distance of $1(\mathrm{~cm})$ between point and point. The value of $8.3(\mathrm{~m})$ used is the best value for our model and resolution that corrects errors and gradients originated from the reconstruction and triangulation of photographs and that do not correspond to the reality in the field. 


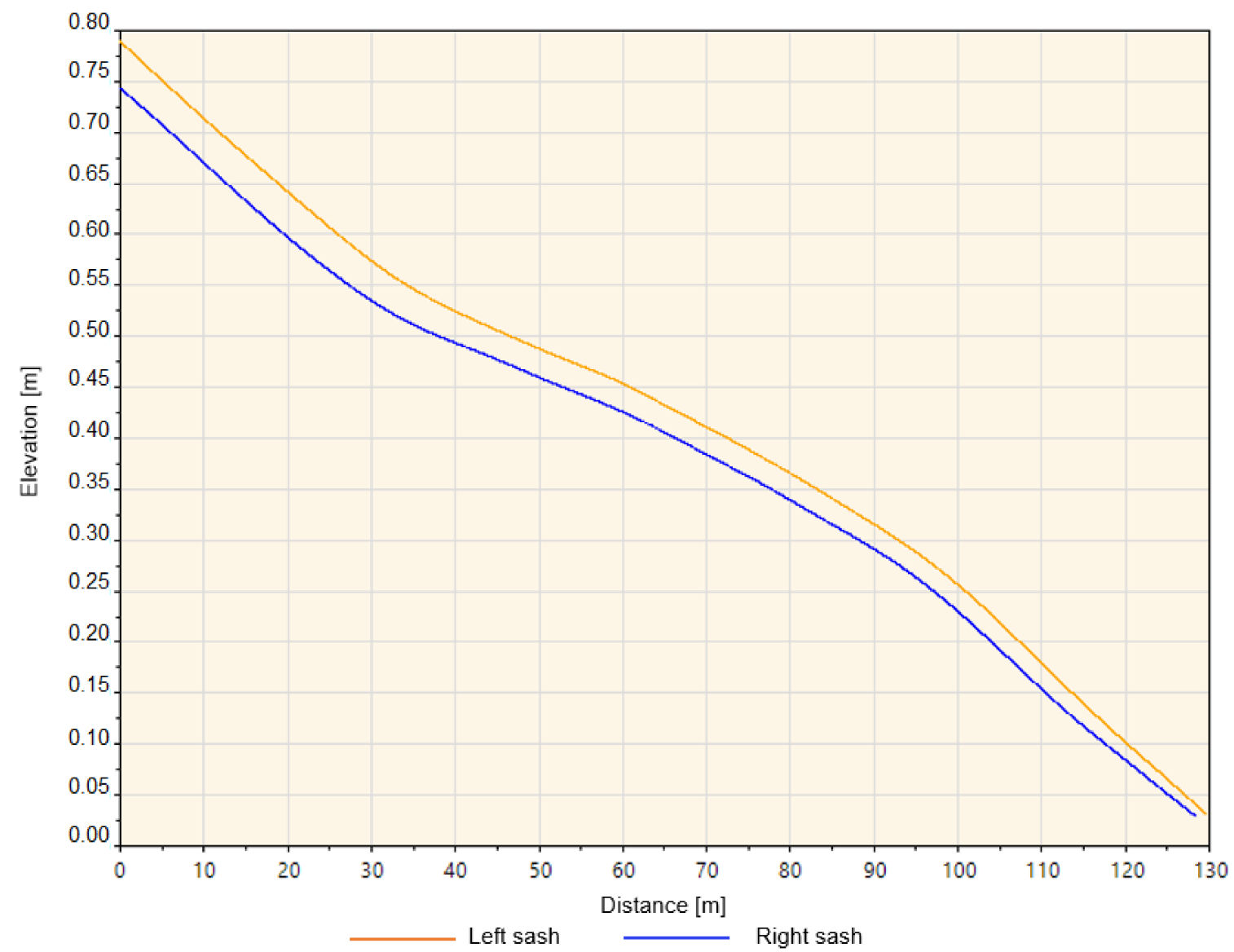

Figure 13. Longitudinal profiles for left and right sashes.

Table 1 then summarizes the results obtained after the proposed experiments and methods are completed comparing the reference value obtained with the Profilometer MLP with our proposed alternative methods.

Table 4 shows that the results obtained through the alternative application of the MERLIN and Quarter Car method are close to the reference results and in no case exceed them.

Table 4. International roughness index (IRI) results obtained according to proposed methods.

\begin{tabular}{cccc}
\hline Axis & $\begin{array}{c}\text { IRI Profilometer MLP }(\mathbf{m} / \mathbf{k m})- \\
\text { (Reference Value) }\end{array}$ & $\begin{array}{c}\text { IRI MERLIN } \\
(\mathbf{m} / \mathbf{k m})\end{array}$ & $\begin{array}{c}\text { IRI QUARTER CAR } \\
(\mathbf{m} / \mathbf{k m})\end{array}$ \\
\hline Right sash & 2.2 & 1.2 & 2.1 \\
Left sash & 1.7 & 1.7 & 1.8 \\
\hline
\end{tabular}

In terms of the error between the results and the reference IRI, Table 5 shows that in the application of the MERLIN method, an error of $45 \%$ was obtained in the right sash, and a zero error was obtained for the left sash. The quarter car method presents a more uniform error for each girdle, making this method preferable to the MERLIN.

Table 5. \% of error obtained according to proposed methods.

\begin{tabular}{ccc}
\hline Axis & MERLIN vs. Reference Value & Quarter Car vs. Reference Value \\
\hline Right sash & $45 \%$ & $5 \%$ \\
Left sash & $0 \%$ & $6 \%$ \\
\hline
\end{tabular}


The lower the IRI values, the lower the road's roughness; therefore, the road has a better texture and comfort for driving. The results obtained underestimate the real roughness of the road, so they are optimistic about the real situation. Therefore, our proposal's application must be applied with caution; it is not yet recommended to certify a new road. However, the method could be a good tool for self-control or monitoring of roads in operation.

\section{Limitations}

According to the conditions of execution of the experiment and the analyses carried out, the research considers the following limitations:

- GCP and checkpoints were not considered for the reconstruction and verification for the 3D model; therefore, there could be uncertainty in the model's location concerning the road points. However, the IRI obtained in this case study through the proposed methodology is similar to the real certified value of the road (provided by the government agency). It is recommended to replicate the experiment in other roads, where certified IRI values (obtained with standardized equipment) are available to generalize the proposed method based on statistical evidence.

- Only Bentley Context Capture software was used since other software licenses were not available at the university where the study was conducted. It is recommended to compare the results of models in other software as they may be different. This is because each software uses its own SfM algorithm for the reconstruction of a 3D model.

- The methodological proposal restricts its application to roads without traffic due to restrictions on flight height and the non-consideration of the elimination of vehicles in the model. The adaptation of the method to perform flights with the road in operation could be evaluated, providing the safety conditions and regulations of the country are considered.

\section{Conclusions}

Two methods have been studied and proposed for the calculation of the international roughness index as efficient alternatives that manage to obtain near-reality results in the selected case study. They allow us to quantify the state of roughness on the pavement, in addition to obtaining as a derived result, a 3D model that is possible to review at any time, avoiding having to go to the place physically. This model can be used to evaluate the conditions of service of a road, allows for the extraction of parameters, which are indicators of their status, contributing to the maintenance and inspection process.

This research provides modern technological techniques and tools to solve problems present in road maintenance, either by lowering the equipment-related costs needed to obtain high-precision results or also by reducing the time spent on measurements needed to achieve international roughness index results. To this end, a literature review was carried out considering general and specific documents, which review the characteristics and considerations of UAVs, photogrammetry, and SfM algorithms for the reconstruction of virtual models and their application in the engineering and construction industry. Moreover, the authors reviewed the current methodologies for obtaining the IRI, application, and use of computer programs that allow the analysis of virtual models and longitudinal profiles. It is concluded that the generated virtual model manages to represent the state of the pavement and is suitable for obtaining the longitudinal profile as well as the calculation of the IRI associated with it because the results obtained belong to the acceptable range of values for semi-new roads. In addition, a wave cutting value is proposed in the longitudinal profile filter equal to $8.3 \mathrm{~m}$.

There are limitations to the application of the proposed methods and are mainly based on the variability of the parameters that the user can consider when obtaining photographic information. This ranges from the type of camera used to the number of photos recorded and time spent on the UAV equipment's operation and affects the quality of the model created and, therefore, the quality of the longitudinal profile extracted. The application of the proposed methods will also be limited due to the weather conditions, which do not allow for optimal results. 
The future work to be carried out following this investigative line corresponds in the first instance to the realization of multiple models for the same route and others, in order to determine the variability that exists between virtual reconstructions and establish fixed parameters that must be used when wanting to obtain the IRI using the present methodology. In addition, it is recommended to adjust the cut-off value in the wave filter that best suits the different longitudinal profiles obtained.

Author Contributions: This paper represents the results of teamwork. M.P.-C., E.A., and F.M.L.R. designed the research methodology. M.P.-C. carried out the literature review, methods, and experiments. All of the authors worked on the results, discussions, and conclusions of the manuscript. Finally, R.F.H., F.M.L.R., and E.A. reviewed and edited the manuscript. All authors have read and agreed to the published version of the manuscript.

Funding: This research was funded by CONICYT grant number CONICYT-PCHA/International Doctorate/201972200306 for funding the graduate research of Muñoz-La Rivera.

Acknowledgments: The authors wish to thank the TIMS space (Technology, Innovation, Management, and Innovation) of the School of Civil Engineering of the Pontificia Universidad Católica de Valparaíso (Chile), where part of the research was carried out. Furthermore, the authors acknowledge to the Ministry of Public Works from Chile.

Conflicts of Interest: The authors declare no conflict of interest.

\section{References}

1. Kubota, S.; Ho, C.; Nishi, K. Construction and usage of three-dimensional data for road structures using terrestrial laser scanning and UAV with photogrammetry. In Proceedings of the 36th International Symposium on Automation and Robotics in Construction (ISARC), Banff, AB, Canada, 21-24 May 2019; pp. $136-143$. [CrossRef]

2. Pasetto, M.; Partl, M.N. Lecture Notes in Civil Engineering Proceedings of the 5th International Symposium on Asphalt Pavements E Environment (APE); Springer: Cham, Swizterland, 2020; ISBN 9783030297787.

3. Sayers, M.; Karamihas, S. Interpretation of Road Roughness Profile Data. Fed. Highw. Adm. 1996, 177.

4. Peffers, K.; Tuunanen, T.; Rothenderger, M.; Chatterjee, S. A Design Science Research Methodology for Information Systems Research. J. Manag. Inf. Syst. 2007, 24(3), 45-77. [CrossRef]

5. De Solminihac, H.E.; Hidalgo, P.; Chamorro, A. Asset valuation of low-volume road networks application to chilean unpaved roads. Transp. Res. Rec. 2007, 1, 72-79. [CrossRef]

6. Sayers, M.W.; Karamihas, S.M. The Little Book of Profiling. Basic Information about Measurements Interpreting Road Profiles; University of Michigan: Ann Arbor, MI, USA, 1998; p. 100.

7. Sayers, M.W.; Gillespie, T.D.; Paterson, W.D.O. Guidelines for Conducting and Calibrating Road Roughness Measurements; The World Bank: Washington, DC, USA, 1986; ISBN 0-8213-0590-5.

8. Ministerio de Obras Públicas de Chile. Manual De Carreteras-Especificaciones y Métodos de Muestreo, Ensaye y Control; Ministerio de Obras Públicas de Chile: Santiago, Chile, 2019; Volume 8.

9. ASTM. Standard Practice for Computing International Roughness Index of Roads from Longitudinal Profile Measurements; ASTM International: West Conshohocken, PA, USA, 2015; Volume 8.

10. Múčka, P. International Roughness Index specifications around the world. Road Mater. Pavement Des. 2017, 18, 929-965. [CrossRef]

11. Townsend, E.; Veliz, C. Determinación de Umbrales de Rugosidad (IRI) Obtenido de Base de Datos de Caminos con Controles Receptivos; Dirección de Vialidad de Coquimbo: Coquimbo, Chile, 2017.

12. Sanchez, I.; Solmnihac, H. De El IRI: Un indicador de la regularidad superficial. Rev. Ing. Constr. 1989, $6,1-16$.

13. De Solminihac, T.H.; Salsilli, R.; Köhler, E.; Bengoa, E. Analysis of pavement serviceability for the AASHTO design method: The Chilean case. Arab. J. Sci. Eng. 2003, 28, 143-160.

14. Del Aguila Rodriguez, P. Metodologia para la Determinación de los Pavimentos-Manual de Usuario Merliner; Camineros S.A.C.: Ayacucho, Peru, 1993.

15. Solomentsev, O.V.; Melkumyan, V.H.; Zaliskyi, M.Y.; Asanov, M.M. UAV operation system designing. In Proceedings of the IEEE International Conference Actual Problems of Unmanned Aerial Vehicles Developments (APUAVD), Kiev, Ukraine, 13-15 October 2015; pp. 95-98. [CrossRef]

16. Dupont, Q.F.M.; Chua, D.K.H.; Tashrif, A.; Abbott, E.L.S. Potential Applications of UAV along the Construction's Value Chain. Procedia Eng. 2017, 182, 165-173. [CrossRef] 
17. Demir, K.A.; Cicibas, H.; Arica, N. Unmanned aerial vehicle domain: Areas of research. Def. Sci. J. 2015, 65, 319-329. [CrossRef]

18. De Melo, R.R.S.; Costa, D.B.; Álvares, J.S.; Irizarry, J. Applicability of unmanned aerial system (UAS) for safety inspection on construction sites. Saf. Sci. 2017, 98, 174-185. [CrossRef]

19. Yang, M.G.; Wei, B.; Cai, C.S. A combined control strategy for vibration mitigations of a suspension bridge induced by vehicle braking force. Balt. J. Road Bridg. Eng. 2015, 10, 118-125. [CrossRef]

20. Gerke, M.; Nex, F.; Remondino, F.; Jacobsen, K.; Kremer, J.; Karel, W.; Huf, H.; Ostrowski, W. Orientation of oblique airborne image sets-Experiences from the ISPRS/Eurosdr benchmark on multi-platform photogrammetry. Int. Arch. Photogramm. Remote Sens. Spat. Inf. Sci. ISPRS Arch. 2016, XL-3/W4, 185-191. [CrossRef]

21. Zheng, Z. The Application Research of Oblique Photogrammetry Technology in Road Planning. IOP Conf. Ser. Earth Environ. Sci. 2018, 192. [CrossRef]

22. Pajares, G. Overview and current status of remote sensing applications based on unmanned aerial vehicles (UAVs). Photogramm. Eng. Remote Sens. 2015, 81, 281-329. [CrossRef]

23. Hernandez-Lopez, D.; Felipe-Garcia, B.; Gonzalez-Aguilera, D.; Arias-Perez, B. An automatic approach to UAV flight planning and control for photogrammetric applications: A test case in the asturias region (Spain). Photogramm. Eng. Remote Sens. 2013, 79, 87-98. [CrossRef]

24. Raczynski, R.J. Accuracy Analysis of Products Obtained from UAV-Borne Photogrammetry Influenced by Various Flight Parameters. Master's Thesis, Norwegian University of Science and Technology, Trondheim, Norway, June 2017.

25. Chambi, E.; Villaroel, S.; La Rivera, F.; Atencio, E. Analysis of optimal fligth parameters of unmanned aerial vehicle (UAV) for detecting potholes in pavements. Appl. Sci. 2020, 10, 4157. [CrossRef]

26. Rosnell, T.; Honkavaara, E. Point cloud generation from aerial image data acquired by a quadrocopter type micro unmanned aerial vehicle and a digital still camera. Sensors 2012, 12, 453. [CrossRef]

27. Mesas-Carrascosa, F.J.; Rumbao, I.C.; Berrocal, J.A.B.; Porras, A.G.F. Positional quality assessment of orthophotos obtained from sensors onboard multi-rotor UAV platforms. Sensors 2014, 14, 22394. [CrossRef]

28. González-Quiñones, J.J.; Reinoso-Gordo, J.F.; León-Robles, C.A.; García-Balboa, J.L.; Ariza-López, F.J. Variables influencing the accuracy of 3D modeling of existing roads using consumer cameras in aerial photogrammetry. Sensors 2018, 18, 3880. [CrossRef]

29. Chen, T.; Shibasaki, R.; Lin, Z. A rigorous laboratory calibration method for interior orientation of an airborne linear push-broom camera. Photogramm. Eng. Remote Sens. 2007, 73, 369-374. [CrossRef]

30. Julge, K.; Ellmann, A.; Köök, R. Unmanned aerial vehicle surveying for monitoring road construction earthworks. Balt. J. Road Bridg. Eng. 2019, 14,1-17. [CrossRef]

31. Gašparović, M.; Gajski, D. Testing of image quality parameters of digital cameras for photogrammetric surveying with unmanned aircrafts. Geod. List 2016, 70, 253-266.

32. Kochi, N. Photogrammetry. Handb. Opt. Metrol. Princ. Appl. Second Ed. 2015, 555-582. [CrossRef]

33. Quirós Rosado, E. Introducción a la Fotogrametría y Cartografía aplicadas a la Ingeniería Civil; Universidad de Extremadura: Cáceres, Spain, 2014; ISBN 9788469713174.

34. Ahmed, M.; Haas, C.T.; Haas, R. Toward low-cost 3D automatic pavement distress surveying: The close range photogrammetry approach. Can. J. Civ. Eng. 2011, 38, 1301-1313. [CrossRef]

35. Bemis, S.P.; Micklethwaite, S.; Turner, D.; James, M.R.; Akciz, S.; Thiele, S.T.; Bangash, H.A. Ground-based and UAV-Based photogrammetry: A multi-scale, high-resolution mapping tool for structural geology and paleoseismology. J. Struct. Geol. 2014, 69, 163-178. [CrossRef]

36. Low, D.G. Distinctive image features from scale-invariant keypoints. Int. J. Comput. Vis. 2004, 60, 91-110. [CrossRef]

37. Agüera-Vega, F.; Carvajal-Ramírez, F.; Martínez-Carricondo, P. Assessment of photogrammetric mapping accuracy based on variation ground control points number using unmanned aerial vehicle. Meas. J. Int. Meas. Confed. 2017, 98, 221-227. [CrossRef]

38. Harwin, S.; Lucieer, A. Assessing the accuracy of georeferenced point clouds produced via multi-view stereopsis from Unmanned Aerial Vehicle (UAV) imagery. Remote Sens. 2012, 4, 1573-1599. [CrossRef]

39. Triggs, B.; McLauchlan, P.F.; Hartley, R.I.; Fitzgibbon, A.W. Bundle Adjustement-A Modern Synthesis. Vis. Algorithms 1999, 298-372. [CrossRef] 
40. Tan, Y.; Li, Y. UAV photogrammetry-based 3D road distress detection. ISPRS Int. J. Geo-Inform. $2019,8$. [CrossRef]

41. Becker, R.E.; Galayda, L.J.; MacLaughlin, M.M. Digital Photogrammetry Software Comparison for Rock Mass Characterization. In Proceedings of the 52nd US Rock Mechanics/Geomechanics Symposium, Seattle, WA, USA, 17-20 June 2018.

Publisher's Note: MDPI stays neutral with regard to jurisdictional claims in published maps and institutional affiliations.

(C) 2020 by the authors. Licensee MDPI, Basel, Switzerland. This article is an open access article distributed under the terms and conditions of the Creative Commons Attribution (CC BY) license (http://creativecommons.org/licenses/by/4.0/). 